\title{
A radiant flow reactor for high-temperature reactivity studies of pulverized solids
}

\author{
John C. Chen and Stephen Niksa \\ High Temperature Gasdynamics Laboratory, Department of Mechanical Engineering, Stanford University, \\ Stanford, California 94303
}

(Received 9 September 1991; accepted for publication 23 November 1991)

\begin{abstract}
Our radiant two-phase flow reactor presents several new possibilities for high-temperature reactivity studies. Most importantly, the thermal histories of the suspension and entrainment gas can be independently regulated over wide ranges. At low suspension loadings, outlet temperatures can differ by hundreds of degrees and gas temperatures are low enough to inhibit hydrocarbon cracking chemistry, so primary products are quenched as soon as they are expelled. With coal suspensions, tars were generated with the highest H/ $\mathrm{C}$ ratio and lowest proton aromaticity ever reported. Alternatively, particles and gas can be heated at similar rates to promote secondary chemistry by increasing particle loading. Simply by regulating the furnace temperature, arbitrary extents of conversion of coal tar into soot were observed for fixed total mass loss. Under both circumstances heat fluxes are comparable to those in large furnaces, so relevant heating rates and reaction times are accessible. Suspensions remain optically thin even for the highest loadings of technological interest because they are only $1 \mathrm{~cm}$ wide. Consequently, the macroscopic behavior remains firmly connected to single-particle phenomena. Mass and elemental closures are rarely breached by more than $5 \%$ in individual runs, so interpretations are not subject to inordinate scatter in the data. The reactor is also well suited for combustion studies, as demonstrated by extents of carbon and nitrogen burnout from $50 \%$ to $100 \%$ for various gas-stream oxygen levels.
\end{abstract}

\section{INTRODUCTION}

Entrained-flow reactors have become the laboratory workhorses for high-temperature reactivity studies with particles. They routinely provide insights into the gasification and combustion of fossil fuels, ${ }^{1-4}$ transformations of minerals, ${ }^{5,6}$ combustion of metals and propellants, ${ }^{7,8}$ and many other two-phase chemical processes. In the most familiar configuration, a laminar or otherwise axisymmetric and well-characterized flowfield passes through a tubular furnace at the temperature of interest. Pulverized solids are fed through a cooled injector onto the centerline of the preheated stream and allowed to react until they are sampled into quench probes. In kinetic rate determinations, residence times are varied by adjusting the distance between injector and sampling point. Sufficient samples for subsequent analysis are easy to acquire, and these systems usually accommodate optical diagnostics through the flow axis. Designs for stream temperatures to $2200 \mathrm{~K}$ with conversion histories resolved into tens of milliseconds are available. ${ }^{1-4}$

Beyond a certain level of accuracy, however, entrained flow reactors are plagued by two generic disadvantages. First, heating rates of the particles are governed by twophase convective mixing phenomena at the injector. Consequently, temperatures through the particle jet vary both radially and axially. Such nonuniform thermal fields cannot be diagnosed directly. They can only be analyzed with complex heat transfer models subject to very large uncertainties because two-phase fluid mechanics determines the heat transfer rate. In the worst situations, heterogeneous chemistry occurs while the fuel is being heated to its ultimate temperature, so uncertain thermal histories translate directly into ambiguous rate parameters. The second generic disadvantage is that primary products of the heterogeneous chemistry undergo uncontrolled secondary reactions in the hot process stream. Pristine products may be unrecoverable, and effects of secondary reactions are often as poorly understood as the source chemistry, so interpretations may be circumscribed.

Both limitations are encountered during the initial stages of coal combustion. As coal thermally decomposes, it expels a diverse mixture of hydrocarbons and heteroatomic gases, including high molecular-weight compounds called tars. Pristine tars are thought to be intact segments of coal's macromolecular matrix, having important implications for structure and reaction mechanisms. But in hot gases tars exhibit a strong propensity to soot and rapidly eliminate their most illuminating features. Despite many studies of coal devolatilization in entrained flow reactors, ${ }^{9}$ the impacts of primary and secondary chemistry are still unresolved. Moreover, coal devolatilization is completed while the fuel is heated to typical combustor temperatures, and the uncertainties in calculated thermal histories have definitely obscured reaction rate determinations. ${ }^{10}$

We developed the radiant two-phase flow reactor to alleviate both of these drawbacks. Here too the suspension is entrained in an idealized flow field. But it is heated by radiation from a near-blackbody enclosure, not by a preheated stream. Conditions are regulated so that the suspension is optically thin, which ensures that individual particles are subjected to the same radiant heat flux. 


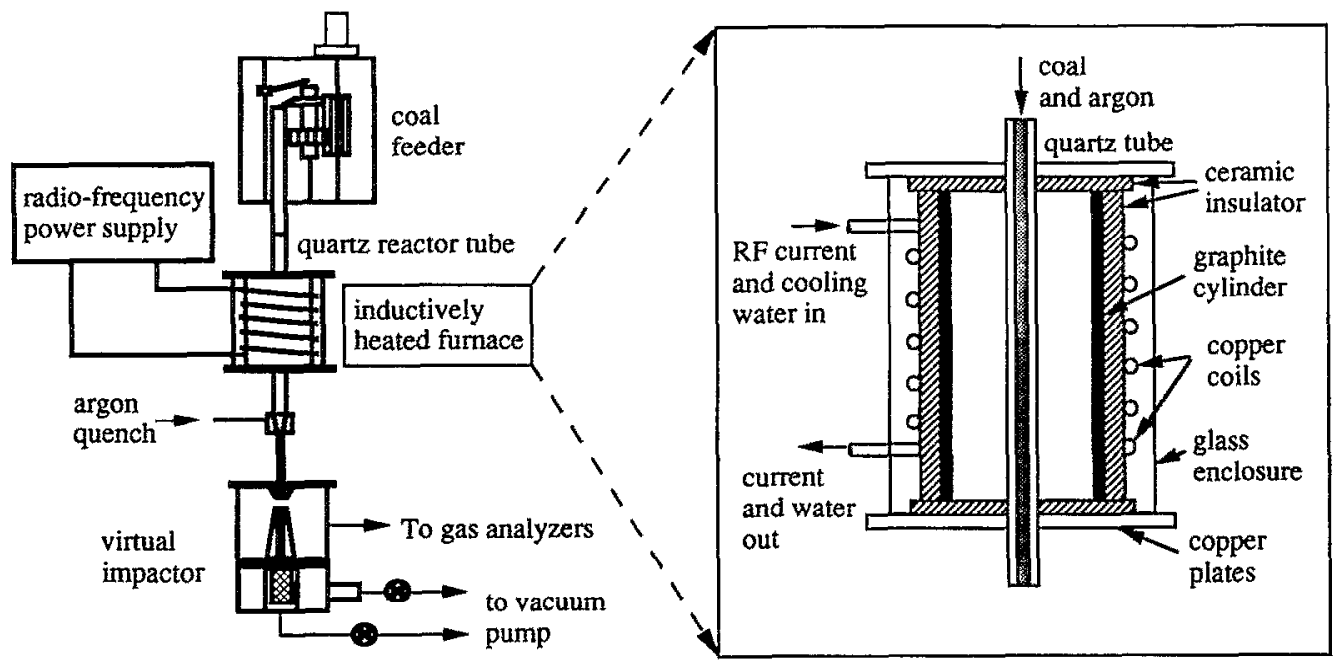

FIG. 1. Radiant two-phase flow reactor.

Consequently, convective mixing phenomena do not govern the suspension's thermal history. The entrainment stream is transparent to radiation, and can be made to remain much cooler than the suspension. Products which have been quenched as soon $\mathrm{s}$ they are expelled into the gas phase can be recovered or, alternatively, the extent of secondary chemistry can be regulated at will.

Schematics and specifications for the furnace and various components in the following section convey the system layout. Then thermal behavior is characterized with a heat transfer analysis of the temperature profiles of particles and entrainment stream for diverse operating conditions. Suspension loading emerges as a key to regulating the contributions from primary and secondary chemistry. This explanation is corroborated by numerous characteristics of coal-derived products. Finally, coal-derived product distributions from primary and secondary pyrolysis and combustion experiments establish the closure of mass and elemental balances for individual runs.

\section{COMPONENT SPECIFICATIONS}

Schematics, characterization studies, and operating procedures are presented for the major components in the following sections. Additional details are available. ${ }^{11}$

\section{A. Radiant furnace}

A schematic of the system appears in Fig. 1. At the top a feeder dumps pulverized particles into an entrainment stream, forming an optically thin suspension which flows downward into a radiant furnace section. The radiant section consists of a quartz tube on the axis of a graphite cylinder which is inductively heated to temperatures to $1850 \mathrm{~K}$. Near-blackbody thermal emission from the graphite rapidly heats the particles as they traverse the furnace. Since the suspension is optically thin, the radiant heat flux to individual particles at any axial position is uniform, and the macroscopic behavior can be interpreted in terms of single-particle phenomena. Also, since the entrainment stream is transparent to the radiation the only means of heating the gas is by convection from the tube wall and particles. Dilute suspensions have little interfacial surface area for interphase heat transfer, so the entrainment gas remains relatively cool and quenches chemistry among primary products as they are expelled. To promote secondary reactions, the suspension loading is increased to enhance interphase heat transfer, and elevate the gas temperature, In addition, residence times are extended for secondary chemistry studies with a longer furnace.

An enlarged schematic of the induction furnace also appears in Fig. 1. Its heating element is a $10-\mathrm{cm}$ (i.d.), 6.4-mm-wall, graphite cylinder (Airco Carbon, grade 780 GL) encased in high-temperature insulation. It is first wrapped in three layers of $2-\mathrm{mm}$ zirconium-oxide felt, then in two layers of $2-\mathrm{mm}$ aluminum-oxide cloth. This arrangement minimizes heat losses and maximizes electrical resistance between the induction coils and graphite by virtue of the low thermal conductivity of zirconium oxide and the high electrical resistivity of aluminum-oxide. With only zirconium-oxide felt, electrical breakdown became problematic after extended service at high temperatures. Watercooled, copper induction coils are wrapped around the insulation, at a nominal spacing of 0.6 turns $/ \mathrm{cm}$. Top and bottom ends of the graphite are insulated with rigid, 12.7mm zirconium-oxide disks. This assembly is mounted within water-cooled copper plates and a quartz housing, as shown in the figure.

Three furnaces of different lengths are now fully operational. The prototype for primary chemistry studies has an overall height of $9.5 \mathrm{~cm}$, and a hot zone (graphite length) which is $5 \mathrm{~cm}$ long. The furnace for secondary chemistry studies has a $12.5-\mathrm{cm}$ hot zone. Studies in turbulent streams are conducted with a $25-\mathrm{cm}$ hot zone, but this reactor is not discussed in this study.

In all of these reactors, the solids flow through a 22 $\mathrm{mm}$ (o.d.) 'quartz tube located on the furnace axis. This quartz withstands exposure to $1850 \mathrm{~K}$ for approximately 1 $\mathrm{h}$; beyond that, the tubes soften and spall when cooled down. Service lives of the quartz at lower temperatures are much longer. During experiments the furnace is purged with argon, to a pressure of 2 -in. $\mathrm{H}_{2} \mathrm{O}$ above atmospheric, to inhibit graphite oxidation.

The graphite is inductively heated by a $450-\mathrm{kHz}, 10-$ 


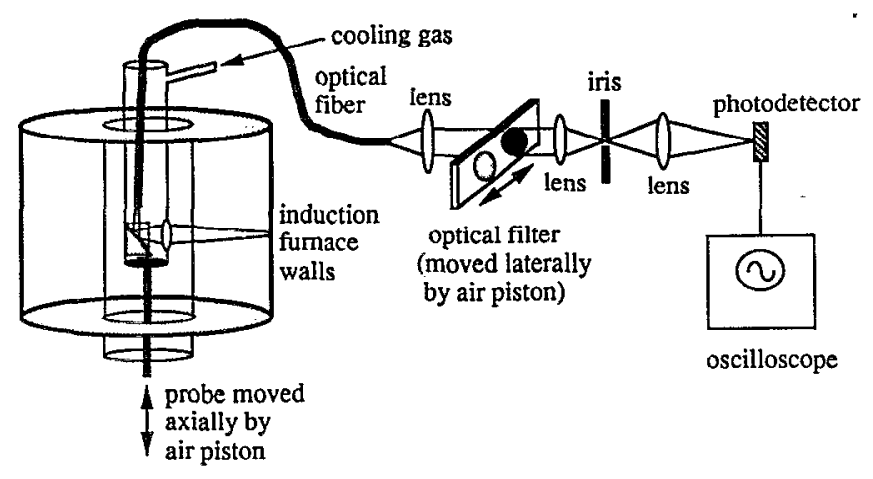

(a)

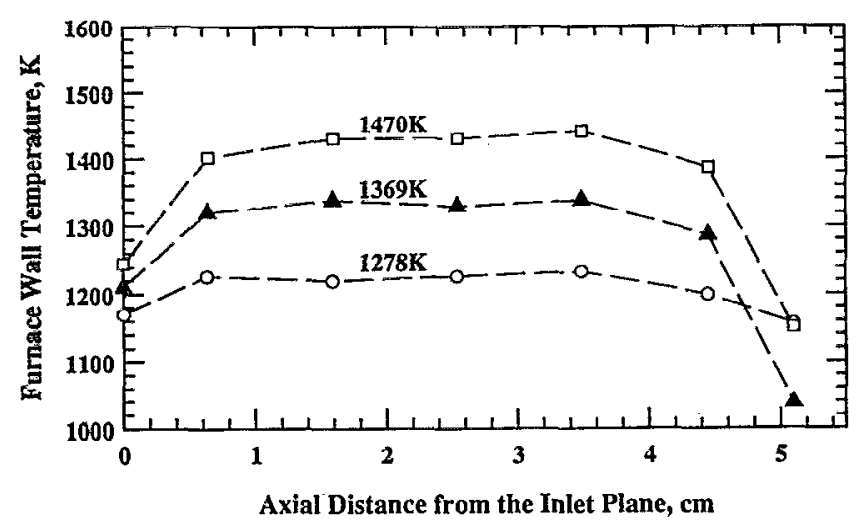

(b)

FIG. 2. (a) Diagnostic for furnace temperature profiles. (b) Furnace wall temperature profiles from the optical probe in (a). Nominal furnace temperatures from a disappearing-filament pyrometer are used to label each curve.

$\mathrm{kW}$ power supply, according to established principles of induction heating. ${ }^{12}$ With graphite, the radio-frequency (rf) current couples very efficiently, and residual rf fields within the furnace are negligible because its thickness is $2_{2}^{1}$ times the "skin depth." "Wall temperatures to $1850 \mathrm{~K}$ are routinely achieved with less than half the available power.

Axial temperature profiles along the inside of the graphite are measured with a two-color pyrometric probe. This diagnostic is laid out in Fig. 2(a). Thermal emission from the hot wall is collected by the achromatic imaging lens and transmitted through a 1-mm optical fiber, collimated, then passed through two narrow-band interference filters ( $40 \mathrm{~nm}, \mathrm{FWHM}$ ) which are alternately shuttled into the path of the light. Thereafter, a lens focuses the emission onto a silicon photodetector. The ratio of the signals at the two effective wavelengths of the filters (655 and $750 \mathrm{~nm}$ ) uniquely determines the wall temperature, following a conventional formula for two-color pyrometry. ${ }^{13}$ This system is calibrated against a tungsten-strip lamp. The probe is traversed along the furnace axis by an air piston, resolving a 4-mm spot at each measurement station.

Figure 2(b) shows temperature profiles measured at three wall temperatures. The temperatures which label each profile were determined with a single-color, disappearing-filament pyrometer sighted onto the midpoint of the outer furnace wall, and signals were adjusted for the emittance of graphite and the reflective losses of the quartz housing. These values are $30-50^{\circ} \mathrm{C}$ hotter than the values monitored within the furnace, probably because of nonuniform power distribution within the furnace wall. ${ }^{12}$ The internal temperature profiles are uniform to within $98 \%$ of their mean temperature except for the outermost $5 \mathrm{~mm}$ at both ends, over which the temperature falls to about $75 \%$ of the mean value because of heat losses to the insulation. The same form is observed at all furnace temperatures, and is expected to apply to hotter furnaces as well. The asymmetry in the profiles is due to misalignment of the probe in the furnace.

\section{B. Solids feeder}

Since thermal histories of the suspension and entrainment stream are sensitive to the suspension loading, it must be controlled. Also, particle size distributions should be as nearly monodisperse as possible to ensure relatively uniform thermal histories among all particles in the suspension. With coal, our feeder maintains rates from 0.25 to $1.25 \mathrm{~g} / \mathrm{min}$. This range is associated with loadings from 0.16 to $1 \mathrm{~kg}$ coal $/ \mathrm{kg}$ gas for typical gas flow rates. Feed rates are exceptionally steady; e.g., at $1 \mathrm{~g} / \mathrm{min}$, the correlation coefficient for the regression of cumulative mass versus time is 0.9999 . For $50-$ and $100-\mu \mathrm{m}$ particles, calibrations differ by only $5 \%$, but calibrations shift significantly for solids of different densities.

As seen in Fig. 3, particles are loaded into a brass tube tapered to $45^{\circ}$ at the open end. As the tube is rotated by a gear assembly and motor, it is forced downward around the Teflon plug to raise the column of particles above the container lip. Particles are removed continuously into a flow tube on the furnace axis as they scrape against an inclined knife edge. The supply tube loaded with particles must first be vibrated for approximately $1 \mathrm{~min}$ with a pneumatic vibrator to homogenize the interparticle voidage. The housing is then flushed with argon to reduce the level of oxygen in the entrainment stream to less than $100 \mathrm{ppm}$.

\section{Stabilizing the particle suspension}

Ideally, the suspension would pass through the furnace as a thin pencil without contacting the walls or leaving any deposits. The concentric tubes delivery assembly in Fig. 3 nearly achieves such circumstances. A 10-mm-diam particle jet issues from the central tube into the reactor tube. After being straightened in a honeycomb, the annular or "sheath" flow stabilizes the particle jet and eliminates deposition on the walls.

Visualization studies in cold flow with diverse loadings, entrainment flow rates, and ratios of jet and sheath velocities identified operating regimes which yielded stable, undispersed suspensions for a given furnace length. (Particle jets eventually become unstable for any inlet condition.) Suspensions were illuminated with a sheet of $\mathrm{HeNe}$ laser light and photographed. Velocity ratios and jet Reynolds numbers $\left(=\rho V_{\text {jet }} d_{\text {tube }} / \mu_{\text {gas }}\right)$ in Fig. 4 define the operating conditions for stable suspensions over the stated 


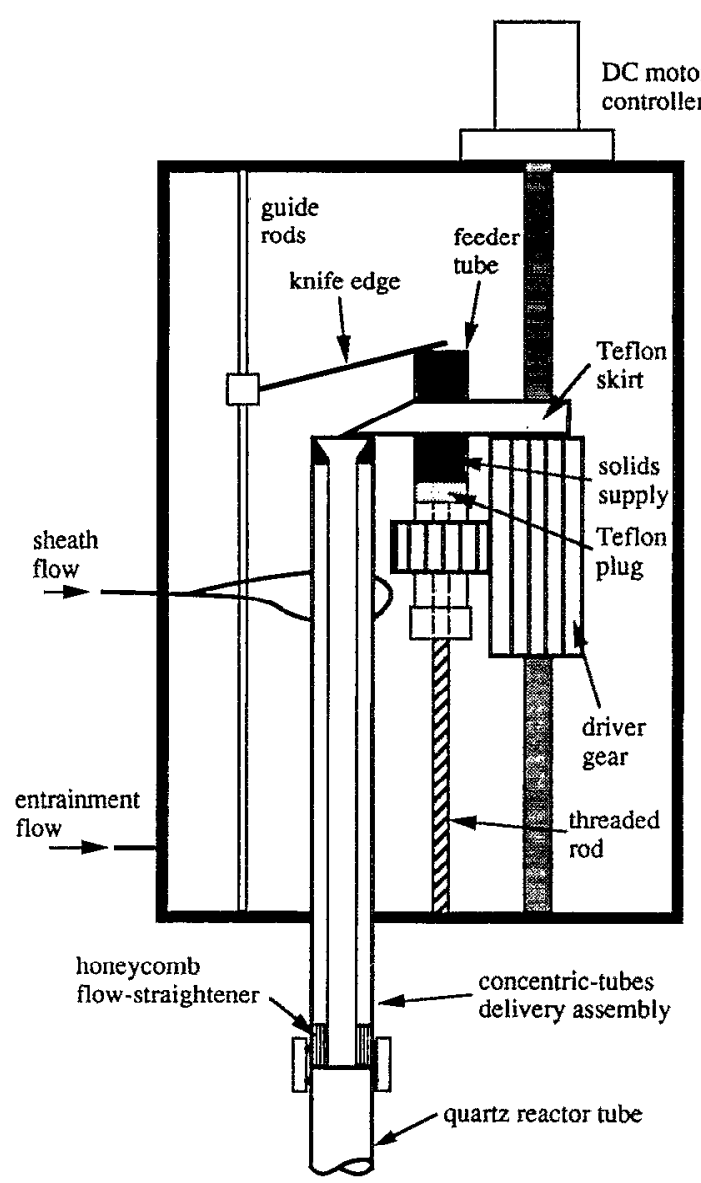

FIG. 3. Solids feeder and the delivery assembly.

lengths. Conditions above and to the right of the curves are unsatisfactory. Conditions downward and to the left of the curves are mostly satisfactory, except for those with very low velocity ratios. It is interesting that velocities at the

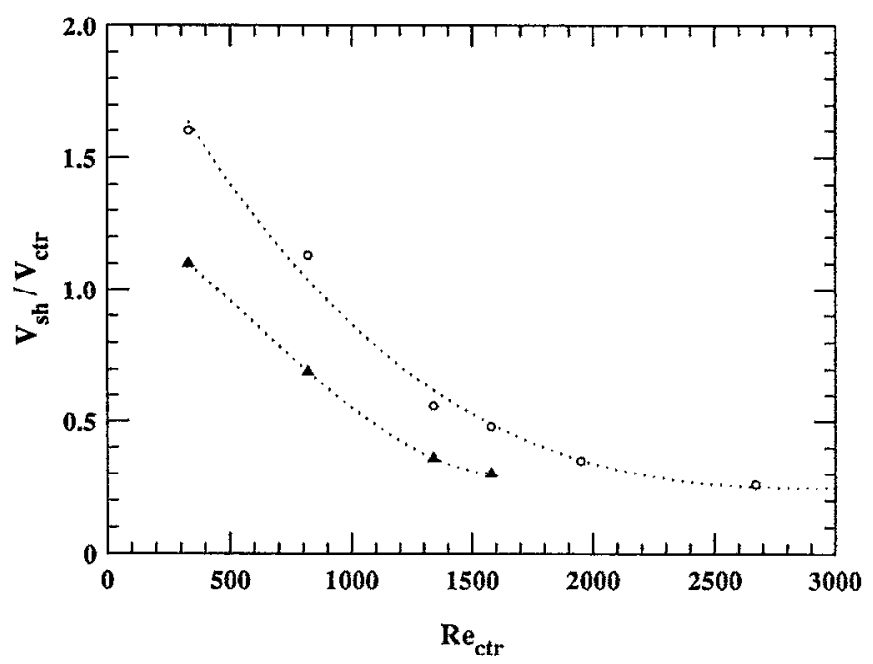

FIG. 4. Inlet conditions in cold flow necessary for stable 1 -cm-wide particle jets $7.6 \mathrm{~cm}(O)$ and $15.2 \mathrm{~cm}(\Delta)$ long. $\mathrm{Re}_{\mathrm{str}}$ is the Reynolds number of the entrainment flow $\left(=V_{\mathrm{ct}} d_{\mathrm{get}} / \vartheta\right)$, and $V_{\mathrm{sh}} / V_{\mathrm{cer}}$ is the ratio of inlet velocities in the sheath and entrainment streams.

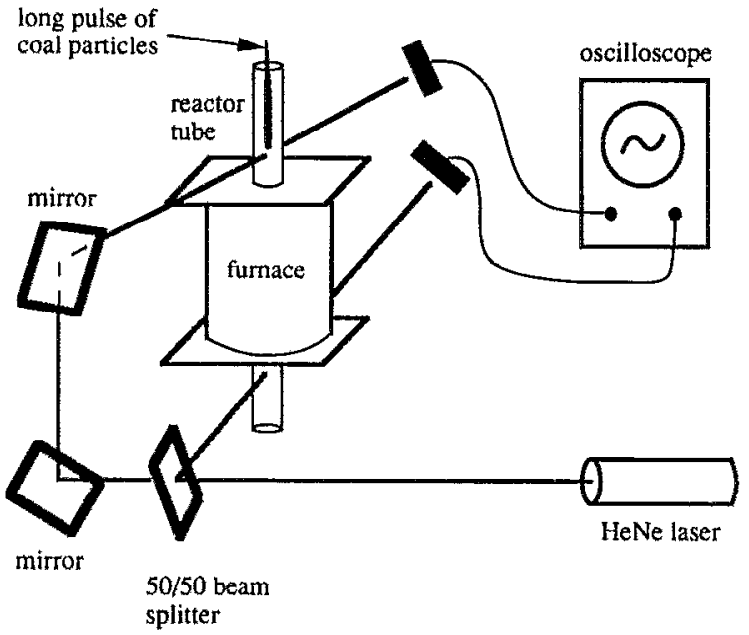

FIG, 5. Diagnostic layout for particle residence time determinations.

inlet must be mismatched more as the Reynolds number is increased to minimize particle dispersion. Moreover, a $15.2 \mathrm{-cm}$ jet cannot be stabilized for Reynolds numbers greater than 1580 (this condition is never encountered in our experimental domain). Velocity ratios at $\frac{2}{3}$ of their transition values in Fig. 4 for cold fow are implemented in high-temperature runs. Although hot flows have not been visualized, the effectiveness of this control strategy is corroborated by the absence of deposits on the wall in the reaction zone for all conditions.

\section{Particle residence time determinations}

Nominal particle residence times are set by the inlet gas flow rate and the furnace length. But nominal values are roughly twice those determined by direct measurements under experimental conditions for several reasons. Boundary layers grow on the tube walls, contracting the cross section of the potential core which carries the suspension, and accelerating it. As the gas heats, its expansion accelerates the flow. The inertia of the suspension, coupled through drag, also accelerates the flow. Radiation is also intercepted by the suspension before and beyond the furnace caps, so the length of the hot zone is somewhat ambiguous. These factors do rationalize the measured values, as shown below.

Measured residence times are assigned as the time interval between the interruption of two $\mathrm{HeNe}$ laser beams $0.75 \mathrm{~cm}$ beyond the endplates by the leading edge of a long pulse of fuel suspension, with the diagnostic in Fig. 5. The downstream station is kept hot with an insulating sleeve with viewing ports to minimize deposition of coal tar. The measurements in Table I show that reaction times from 50 to $100 \mathrm{~ms}$ can be resolved into increments of only several milliseconds in the $5-\mathrm{cm}$ furnace.

\section{E. Quenching}

At the furnace outlet, argon is injected through a quench nozzle into the process stream, rapidly quenching 
TABLE I. Summary of operating conditions.

\begin{tabular}{|c|c|c|c|c|c|c|}
\hline \multirow{2}{*}{$\begin{array}{l}\text { Residence } \\
\text { time } \\
\text { (ms) }\end{array}$} & \multirow{2}{*}{$\begin{array}{l}\text { Central } \\
\text { jet velocity } \\
(\mathrm{m} / \mathrm{s})\end{array}$} & \multicolumn{4}{|c|}{ Flow rates (standard liter/min) } & \multirow[b]{2}{*}{$\begin{array}{l}\text { Impactor } \\
\text { inlet } R e\end{array}$} \\
\hline & & $\begin{array}{l}\text { Entrainment } \\
\quad \text { flow }\end{array}$ & $\begin{array}{l}\text { Sheath } \\
\text { flow }\end{array}$ & $\begin{array}{c}\text { Quench } \\
\text { flow }\end{array}$ & $\begin{array}{l}\text { Total } \\
\text { flow }\end{array}$ & \\
\hline \multicolumn{7}{|c|}{ Primary pyrolysis studies, $5-\mathrm{cm}$ furnace: } \\
\hline 89.0 & 0.18 & 0.85 & 2.21 & 15.8 & 19.9 & 4730 \\
\hline 86.5 & 0.25 & 1.18 & 2.93 & 15.8 & 20.9 & 5000 \\
\hline 83.0 & 0.33 & 1.56 & 3.83 & 15.8 & 22.2 & 5310 \\
\hline 77.0 & 0.40 & 1.88 & 4.52 & 17.7 & 25.1 & 6000 \\
\hline 72.0 & 0.50 & 2.36 & 5.23 & 16.5 & 25.1 & 6000 \\
\hline 66.0 & 0.67 & 3.16 & 6.06 & 14.9 & 25.1 & 6000 \\
\hline 61.0 & 1.0 & 4.71 & 6.50 & 12.9 & 25.1 & 6000 \\
\hline 56.0 & 2.0 & 9.42 & 6.79 & 7.9 & 25.1 & 6000 \\
\hline \multicolumn{7}{|c|}{ Secondary pyrolysis studies, $12-\mathrm{cm}$ furnace: } \\
\hline$\ldots b$ & 0.18 & 0.85 & 2.21 & 15.8 & 19.9 & 4730 \\
\hline
\end{tabular}

${ }^{2}$ Determined at $1840 \mathrm{~K}$ wall temperature.

'Measured residence times vary from 175 to $155 \mathrm{~ms}$ for furnace temperatures from 1480 to $1740 \mathrm{~K}$.

'Includes a fixed flow through the transpiring tube of 1.0 standard liter/min.

all chemistry and nucleating condensibles into fine aerosol. Particle cooling rates range from 3000 to $9000 \mathrm{~K} / \mathrm{s},{ }^{11}$ depending on the proportions of quench gas to process stream and the particle loading. The products are then directed into the virtual impactor through a transpiring tube assembly to eliminate deposition. The transpiring tube is a $19-\mathrm{mm}$ (o.d.), $12.7-\mathrm{mm}$ (i.d.), sintered stainless-steel tube with a nominal pore size of $5 \mu \mathrm{m}$. A converging Teflon nozzle after this tube converges the stream to the inlet diameter of the virtual impactor.

Swirl upstream of the quench nozzle penetrated into the furnace in prototypes with discrete injection ports, but is absent with the slit injection in the final design. Uniform flow into the core is ensured by having a plenum cross section that is 3.5 times the slit area. Even with this design, as the sheath and entrainment flow rates are lowered to achieve the longest residence times (in Table I), the quench flow must be reduced by up to $22 \%$ to eliminate flow disturbances in the furnace. At all other flow rates, the sum of quench, sheath, and entrainment flows is fixed. Turbulence in the nozzle promotes mixing as well as aerosol deposition. Characterization studies with various coals, presented in Table II, show that $2-4 \mathrm{wt} \%$ of the coal feed is lost, regardless of the aerosol yield. Assuming that the deposits are random samples of the aerosol, we add 2 wt \% to all aerosol yields greater than $4 \mathrm{wt} \%$ to account for the loss.

\section{F. Virtual impactor}

Products are segregated into bulk solid particles, fine aerosol (when condensibles are present), and nonconden-

TABLE II. Deposition of aerosol in the quench nozzle.

\begin{tabular}{cc}
\hline $\begin{array}{c}\text { Aerosol yield } \\
\text { (wt \% coal) }\end{array}$ & $\begin{array}{c}\text { Deposit } \\
\text { (wt \% coal) }\end{array}$ \\
\hline 12.0 & 3.4. \\
17.0 & 2.8 \\
19.4 & 2.7 \\
24.4 & 2.0 \\
\hline
\end{tabular}

sible gases in the aerodynamic classifier shown in Fig. 6; complete drawings appear in Ref. 11. Beyond the inlet port, the process stream is split between opposing nozzles. $95 \%$ of the flow follows the streamlines in the sketch into the annulus. Since the aerosol particles are typically a few micrometers in diameter, they are convected into the annulus and ultimately onto filters. Particles with sufficient inertia, viz., residual solid particles, pass through the impaction surface into a wire-mesh basket. The flow rate through the center is monitored with a mass-flow transducer, and adjusted during a run to maintain the desired flow split.

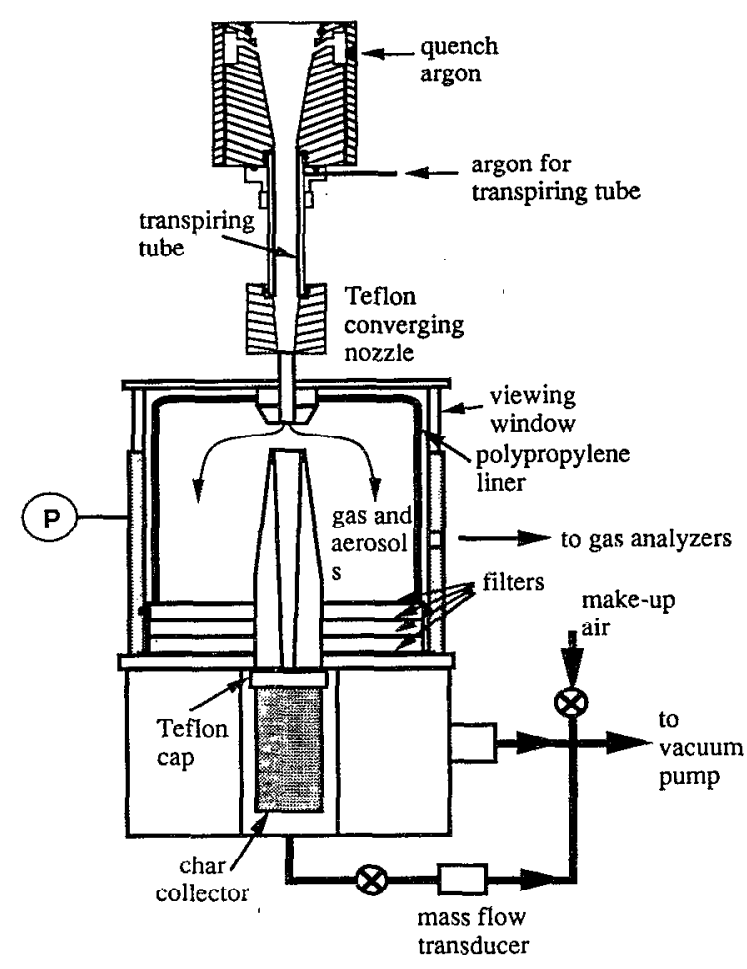

FIG. 6. Quench nozzle coupled via the transpiring-tube assembly into the virtual impactor. 


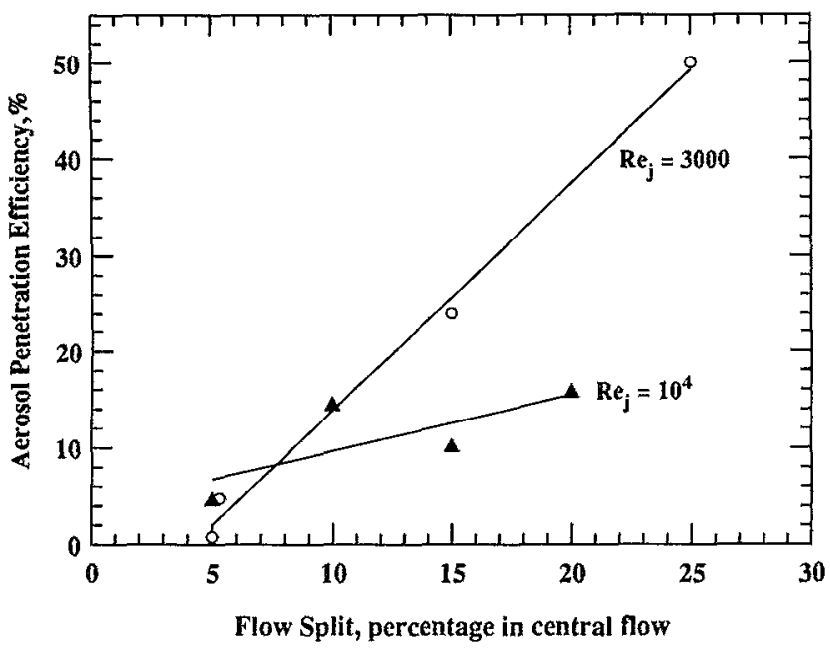

FIG. 7. Aerosol penetration efficiencies into the impactor's central channel for $2.8 \mu \mathrm{m}$, glycerin/water aerosol at two inlet flow conditions.

Coal tar aerosol is recovered on a four-stage assembly of glass-fiber filters (Whatman, EPM2000) and a polypropylene liner. Under most conditions, $90 \%$ of the aerosol is collected on the filters. Even though the aerosol does not penetrate a single filter element, multiple stages are needed to manage the increasing flow resistance as the aerosol accumulates. The top three stages are punctured with pushpins $\left(\sim 2\right.$ holes $\left./ \mathrm{cm}^{2}\right)$ to decrease their flow resistance as aerosol collects. Even so, most of the aerosol deposits onto these stages. The final stage scavenges the stream at the size threshold of the filters (efficiency $=99.93 \%$ at 0.3 $\mu \mathrm{m})$.

Noncondensible products are sampled into heated multiport sampling valves through a port behind the plastic liner. A filter housing attached to the port is loosely packed with glass wool backed by a glass-fiber disk to remove aerosol. Less than $7 \%$ of the gas flow is sampled, so flow patterns within the impactor are hardly perturbed, although aerosol yields are corrected for the amount withdrawn into this line.

The impactor's performance was evaluated in cold flow, first to demonstrate that large particles cannot be diverted into the annulus. With $50-\mu \mathrm{m}$ pulverized coal particles, the observed collection efficiency exceeded $97 \%$ for all Reynolds numbers (3000-10 000), Stokes numbers (16 ), and ratios of annulus flow to total flow $(0.75$ to 0.95$)$. Performance with larger and denser particles is even better. ${ }^{14,15}$ Penetration efficiencies of synthetic aerosol into the central channel were also measured and compared to values assigned from the flow split. The aerosol was generated by atomizing a glycerin/water mixture (3:1 by weight) in a medical nebulizer (Burton Medical Products, part No. 052 1020). The number-average median diameter of the aerosol is $2.8 \mu \mathrm{m}$, which corresponds to Stokes numbers between 0.07 and 0.2 , depending on the gas flow rates. Efficiencies observed at two extreme inlet conditions for various flow splits appear in Fig. 7. Ideally, efficiency matches the flow split, as seen for the higher inlet Reynolds number. However, at $\mathrm{Re}_{j}=3000$, significantly more aerosol is diverted out of the annulus than expected based on the flow splits. Consequently, in experiments, only $5 \%$ of the flow passes into the central channel and, as seen in Table I, inlet Reynolds numbers are held between 4730 and 6000.

Conversions of particle mass and yields of aerosol are based on the weight gain of their respective collection elements, and the total mass fed during the run. Aerosol yields are adjusted for the $95 \%$ flow split and the portion which passes into the gas sampling line, and for deposition in the quench nozzle (by adding $2 \mathrm{wt} \%$ ).

\section{G. Product analyses}

The analysis train described in this section has been tailored to complex hydrocarbon mixtures. Noncondensible gases sampled from the virtual impactor are quantified by NDIR and chemiluminescence analyzers, and by gas chromatography (GC). Gas mixtures for $\mathrm{GC}$ analyses are trapped in a 16-loop sampling valve heated to $60^{\circ} \mathrm{C} . \mathrm{C}_{1}-\mathrm{C}_{4}$ hydrocarbons and $\mathrm{HCN}$ are chromatographed on a 1.83$\mathrm{m}$, Porapak Q column; a separate injection onto a $1.83-\mathrm{m}$, Porapak $\mathrm{N}$ column quantifies ethylene and acetylene. "Oils," defined as hydrocarbons with carbon numbers of 5 and higher remaining in the gas phase under the conditions in the impactor, are monitored by their signal from a flame ionization detector (FID) calibrated with pentane. This value is reduced by the yields of $\mathrm{C}_{1}-\mathrm{C}_{4}$ hydrocarbons (determined by a separate sample injection) to arrive at the oils yield. The concentrations of $\mathrm{CO}, \mathrm{CO}_{2}$, and $\mathrm{H}_{2} \mathrm{O}$ in the effluent are determined on-line with NDIR analyzers. NO is determined with a chemiluminescence analyzer.

Carbon, hydrogen, and nitrogen contents of solid products are determined with an elemental analyzer calibrated with acetanilide. Tars are recovered by extraction with tetrahydrofuran in an ultrasonic bath, followed by concentration and evaporation to isolate the samples. Tar hydrogen distributions are determined by ${ }^{1} \mathrm{H}$-NMR spectroscopy, using a Varian XL-400 spectrometer operating at $400 \mathrm{MHz}$ with an average acquisition time of $1.5 \mathrm{~s}$, and tabulated chemical shifts. ${ }^{16}$ Deuterated pyridine is the solvent of choice because it is available in the requisite purity and completely dissolves these tars, and the signal from water in pyridine does not interfere with spectral features of tars.

\section{SYSTEM PERFORMANCE}

Uncertainties in the thermal histories and closure of mass and elemental balances are discussed in turn in the following sections. Thermal histories are especially important because distinguishing primary and secondary chemistry is largely a matter of independently regulating the thermal histories of solids and the entrainment stream. For studies of primary chemistry, residence times are varied at fixed furnace temperature. Thermal histories in a series of runs have nearly the same heating rate, but the suspension achieves different temperatures at the outlet in each case. Higher temperatures are achieved as residence times are 
extended, but outlet temperatures are always well below the furnace temperature. In runs to study secondary chemistry, entrainment gas flow rate is fixed while furnace temperatures are increased. The thermal histories among such cases have similar heating rates but different reaction times at various ultimate temperatures. Calculated thermal histories for studies of primary and secondary chemistry are presented below.

Diagnostics to measure these temperatures are feasible but difficult to implement. Suspension pyrometry at the furnace outlet entails substantial corrections for scattered furnace emission. Gas temperature measurements are also complicated by the intense radiation, and by deposits of heavy hydrocarbons onto thermocouples. In lieu of data, the heat transfer analysis in the next section explains why suspension loading is the key to thermal control in the radiant flow reactor. Calculated heat fluxes and heating rates are also seen to be comparable to those in industrial furnaces.

\section{A. Calculated thermal histories}

Our analysis is based on the heat transfer to an individual particle moving on the axis of the flow reactor. It assigns the temperatures and velocities of the particle and gas, and particle residence times. These thermal histories pertain to the entire suspension provided that the loading is below $\sim 1200$ particles $/ \mathrm{cm}^{3}$ for $90-\mu \mathrm{m}$ coal particles, at which point its radiant absorption becomes significant and it is no longer optically thin in some directions. The analysis proceeds in two parts. The radiant flux from the furnace onto the flow axis is defined by applying the net radiation method ${ }^{17}$ to the furnace enclosure, without considering the suspension. This decoupling is justified for optically thin suspensions, which absorb insignificant amounts of the radiation. Then the radiant flux is combined with other fluxes within and between particles and gas to define their thermal histories.

The radiation analysis includes exchange among (1) the graphite wall, regarded as gray, (2) the zirconia end plates, which are also gray, and (3) the quartz flow tube, which is transmitting but only into the near infrared. Convection from the quartz tube to the entrainment stream is included. The radiant flux onto the centerline of the $5-\mathrm{cm}$ furnace appears in Fig. 8. With the graphite at $1840 \mathrm{~K}$, the maximum flux is $60 \mathrm{~W} / \mathrm{cm}^{2}$, similar to the $50-100 \mathrm{~W} / \mathrm{cm}^{2}$ estimated for coal-fired burners in utility boilers. One third of the heat flux is transmitted from the graphite through the quartz, and another third comes from both end plates. The remainder emanates directly from the quartz tube. Significant heat fiuxes escape through the top and bottom ports of the quartz tube, which shows up in the temperature profiles of particles. Consequently, the physical length of the reaction zone does not equal the distance over which the suspension is heated, although these lengths do converge as the length of the graphite element is increased.

The net radiation flux enters into the energy balance for an entraincd particle on the centerline, as do convcction

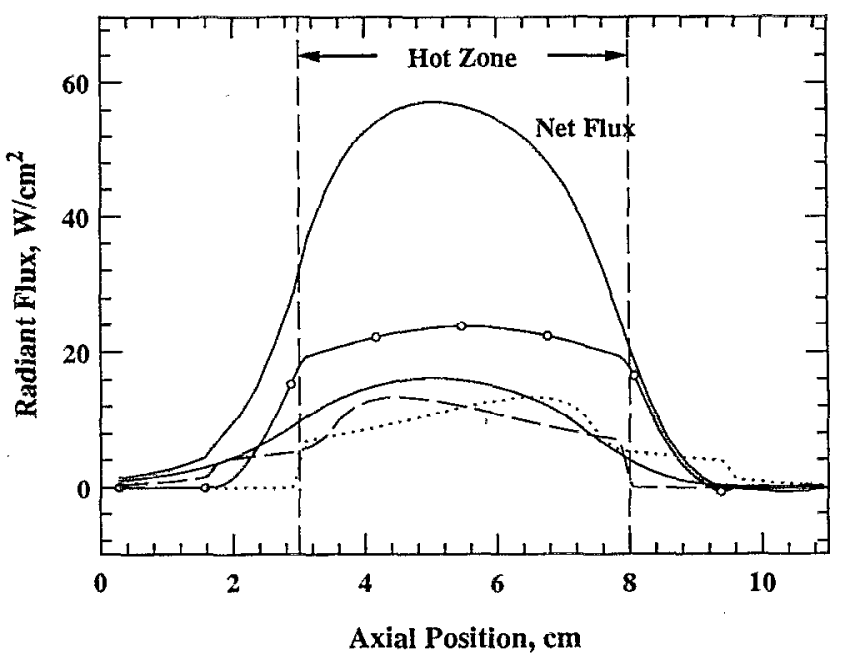

FIG. 8. Radiant fluxes onto the centerline of the furnace at $1840 \mathrm{~K}$. Dashed vertical lines denote the extent of the hot zone. The net flux (upper solid curve) is composed of fluxes from the graphite (solid curve with circles), lower (dashed curve) and upper (dotted curve) zirconia endplates, and the quartz tube (lower solid curve).

losses to the entrainment stream and the pyrolysis endotherm. These fluxes sum to match the thermal capacitance, according to

$$
\rho_{p} c_{p} \frac{V_{p}}{A_{p}}\left(v_{p}\right) \frac{d T_{p}}{d z}=R_{\mathrm{qt}}+R_{\mathrm{tot}}-h_{p}\left(T_{p}-T_{g}\right)-\Delta H_{p} \dot{m}_{v}
$$

where $\rho_{p}$ is the particle bulk density, $c_{p}$ is the specific heat of coal, $V_{p}, A_{p}$ are the particle volume and surface area, respectively, $T_{p}, T_{g}$ are the particle and gas temperatures, respectively, $R_{\text {qt }}$ is the net radiant flux from the quartz tube, $R_{\text {tot }}$ is the net radiant flux from end plates, graphite element, and surroundings,

$$
h_{p}=\frac{\lambda_{g}}{a} \frac{B_{v}}{\exp \left(B_{v}\right)-1}
$$

is the heat transfer coefficient for a devolatilizing particle, $\lambda_{g}$ is the gas thermal conductivity, $a$ is the particle radius,

$$
B_{v}=\dot{m}_{v} /\left(\bar{\rho}_{v} D / a\right)
$$

is the scaled volatile flux, $\dot{m}_{v}$ is the volatiles mass flux through the particle surface, $\vec{\rho}_{v}$ is the average gas density, $D$ is the mass diffusivity of volatiles, and $\Delta H_{p}$ is the heat of pyrolysis.

In the thermal capacitance, the time derivative has been expressed in terms of axial position, $z$, so the local particle velocity, $v_{p}$, appears. The ratio of volume to surface area is evaluated for spheres. Intraparticle temperature gradients are negligible for coal particles in the pulverized fuel size grade, so internal conduction has been omitted. The convective heat flux is evaluated in the conduction limit, with a blowing factor to represent the impact of outflowing volatiles. The volatiles flux needed to assign the heat transfer coefficient is computed from the distributed activation energy model. ${ }^{18}$ Particle density variations due to mass loss and swclling is taken into account. The parti- 
cle volume is increased by $20 \%$ at the onset of devolatilization, consistent with observations for swelling coals. Otherwise, average thermophysical properties which depend only on temperature are implemented at each axial position. At only $100 \mathrm{cal} / \mathrm{g},{ }^{19}$ the pyrolysis endotherm is negligible for coals.

Through the convection term in Eq. (1), the energy balances for particles and gas are coupled, and must be solved simultaneously. The balance for the gas phase matches its thermal capacitance with fluxes due to convection from the suspension and from the quartz wall. These fluxes are applied to the incremental gas volume which extends across the diameter of the flow channel to define the axial profile of average gas temperature. The balance is

$$
\rho_{g} c_{g} v_{g} \frac{d T_{g}}{d z}=N_{p} A_{p} h_{p}\left(T_{p}-T_{g}\right)+\left(\frac{2}{r_{q}}\right) h_{t}\left(T_{q}-T_{g}\right)
$$

where, in addition to previously defined variables, $\rho_{g}$ is the gas density, $c_{g}$ is the gas specific heat, $N_{p}$ is the particle loading, $r_{q}$ is the quartz tube radius, $h_{t}$ is the heat transfer coefficient for developing flow in a tube, and $T_{q}$ is the quartz tube temperature at a given axial location.

Calculated temperature profiles appear in Fig. 9. The case for an inlet suspension loading of 300 particles $/ \mathrm{cm}^{3}$ in Fig. 9 (a) is an actual operating condition for primary chemistry studies. Particles begin heating $1 \mathrm{~cm}$ upstream of the inlet plane, consistent with the radiant flux in Fig. 8. Even though their heating rate exceeds $10^{4} \mathrm{~K} / \mathrm{s}$, the particle temperature at the outlet is well below the $1840-\mathrm{K}$ wall temperature. Having been designed for decomposition studies during transient heating, this furnace does not impart an isothermal stage to the suspension. Most importantly, the gas heats at only $2300 \mathrm{~K} / \mathrm{s}$ and reaches only 550 $\mathrm{K}$ at the outlet. At this temperature, secondary reactions are too slow to affect coal-derived products. ${ }^{20}$ The $400-\mathrm{K}$ disparity between particle and gas temperatures is an effective driving force for quenching. With coal at this operating condition, we recovered pyrolysis tars having the lowest proton aromaticity and highest $\mathrm{H} / \mathrm{C}$ ratio ever reported, no soot in the aerosol, and virtually no $\mathrm{HCN}$ in the noncondensibles-all of which strongly corroborate the minimal extents of secondary chemistry achieved in this experimental configuration.

Secondary chemistry can be promoted at will, as evident in the temperature profiles in Fig. 9(b). The hot zone has been extended to $12 \mathrm{~cm}$, and the inlet loading has been increased to 1200 particles $/ \mathrm{cm}^{3}$. Once again, particle heating rates are $\sim 10^{4} \mathrm{~K} / \mathrm{s}$. But due to the large interfacial surface for convection associated with the high loading and the extended transit time, particles and gas heat at comparable rates to relatively high temperatures. Even though the hot zone is cooler, the stream gets much hotter than in the primary chemistry studies. Primary hydrocarbon products rapidly decompose when heated above $900 \mathrm{~K}^{21} \mathrm{Ac}$ cordingly, at the conditions in Fig. 9(b), soot constitutes nearly the entire aerosol fraction, not tar, and acetylene and hydrogen are the most abundant noncondensible hy-

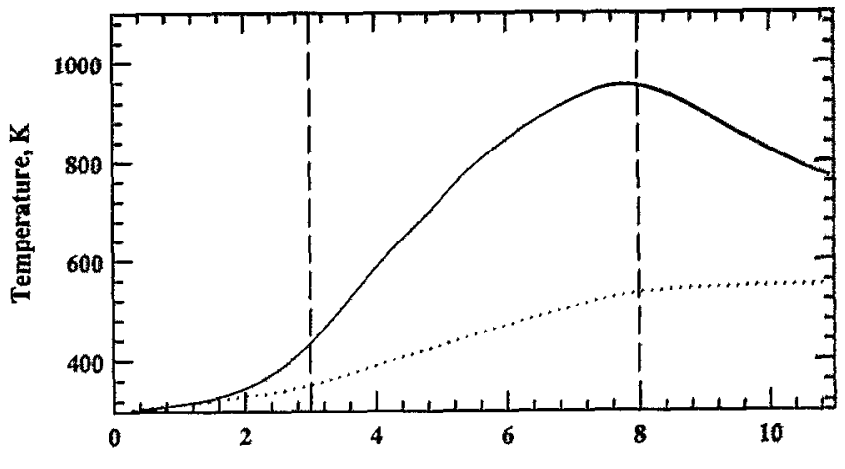

(a)

Axial Position, $\mathrm{cm}$

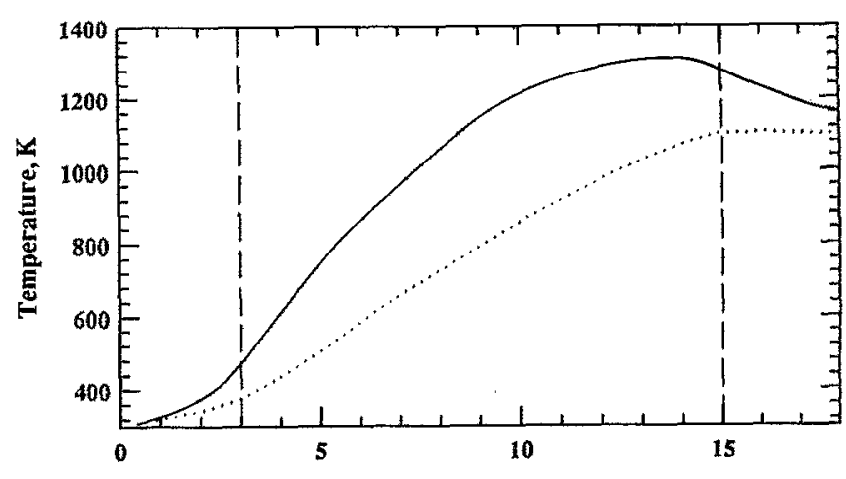

(b)

Axial Position, $\mathbf{c m}$

FIG. 9. (a) Particle (solid curve) and gas (dotted curve) temperature profiles for studies of primary pyrolysis in an $1840 \mathrm{~K}$ furnace. Inlet loading is 300 particles $/ \mathrm{cm}^{3}$, and the residence time is $86.5 \mathrm{~ms}$. Dashed lines denote the length of the hot zone. (b) Particle (solid curve) and gas (dotted curve) temperature profiles for studies of secondary pyrolysis in a $1740 \mathrm{~K}$ furnace. Inlet loading is 1200 particles $/ \mathrm{cm}^{3}$. Dashed lines denote the length of the hot zone.

drocarbons. Simply by reducing the hot-zone temperature, the entire range of conversion of tar into soot can be investigated. 11,22

The influence of particle loading is highlighted further by the yields of coal products in Fig. 10. As loadings were increased from 1000 to 4200 particles $/ \mathrm{cm}^{3}$, both total weight loss and the yield of tar aerosol from $55-\mu \mathrm{m}$ Illinois No. 6 coal monotonically increased. Higher yields indicate hotter particle temperatures at the outlet, as expected for higher loadings from our heat-transfer analysis.

In kinetic studies, temperature profiles are converted to thermal histories by assigning residence times, which involve the unequal velocities of gas and particles assigned with force balances. Particle inertia balances forces due to gravity and the drag force in the Stokes limit for pulverized fuels. This balance is incorporated into the system of equations. However, the balance which determines gas velocities in the radiant flow reactor is complicated by (1) having the suspension within the core of the flow only, (2) a shear layer between two separate flows at the inlet, and (3) the developing boundary layer on the tube wall. A momentum balance for this system would not be quantitatively 


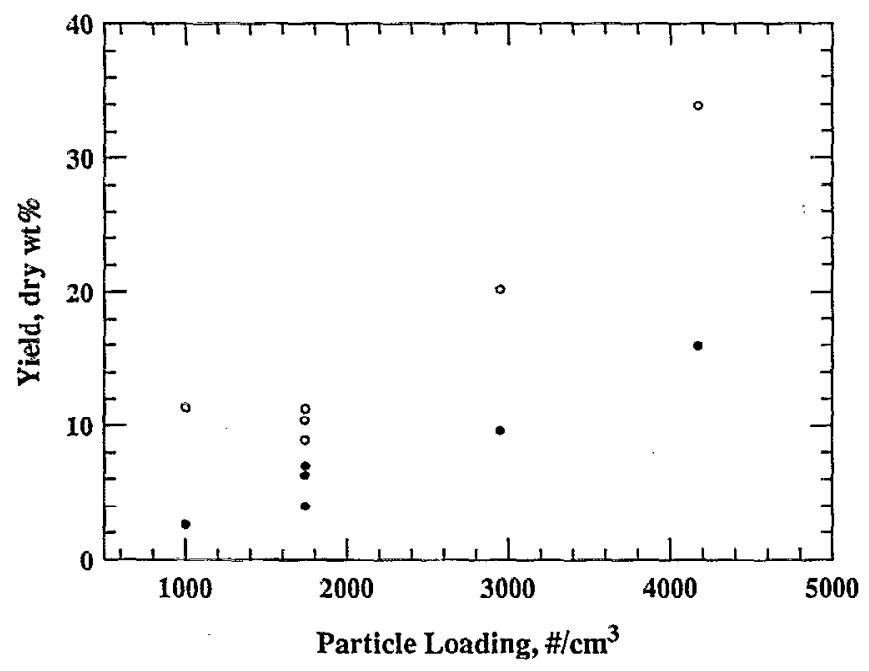

FIG. 10. Weight loss $(O)$ and tar yield $(0)$ at various loadings. The furnace temperature is $1740 \mathrm{~K}$, and measured residence times are $74-80$ $\mathrm{ms}$, decreasing with increasing loading.

reliable given the uncertainties at the two-phase shear layer alone.

Alternatively, we developed a correlating function to express the acceleration of the gas due to the contracting core for potential flow on the centerline, and to thermal expansion. Mass conservation stipulates that the mass flow rate at the inlet is preserved throughout. Consequently, velocities increase in inverse proportion to the diminishing channel cross section, and the diminishing gas density. The effective cross section decreases as a result of the developing boundary layer along the tube. The channel's "virtual contraction" is gauged by the displacement thickness, given for flow over plates by the well-known Blasius solution. ${ }^{23}$ We incorporated the same scaling with a different numerical prefactor for the contraction of the potential core within the quartz tube. The gas density is described by the ideal gas law, neglecting the small differences among the molecular weights of volatile products and the argon carrier gas. The expressions combine into the following expression for the gas velocity:

$$
\begin{aligned}
& v_{g}=\left(v_{g} \frac{A_{t}}{T_{g}}\right)_{\mathrm{ref}} \frac{T_{g}}{\pi\left(r_{q}-\delta^{*}\right)^{2}}, \\
& \delta^{*}=2.24 \sqrt{\mu z / \rho_{g} v_{g}} .
\end{aligned}
$$

Subscript "ref" refers to values at a reference location, such as the inlet. The displacement thickness, $\delta$, defined by Eq. ( $3 b$ ) was assigned by matching the calculated and measured particle residence times in cold flow. Its numerical prefactor is $30 \%$ higher than the factor of 1.72 from the Blasius solution, which is reassuring because tube flow should develop faster based on geometrical considerations.

Comparisons among predicted and measured residence times appear in Fig. 11. In Fig. 11(a) predicted residence times for the complete range of entrainment velocities for primary chemistry studies usually exceed measured values, by up to $20 \%$ at the lowest gas velocity. The discrepancies

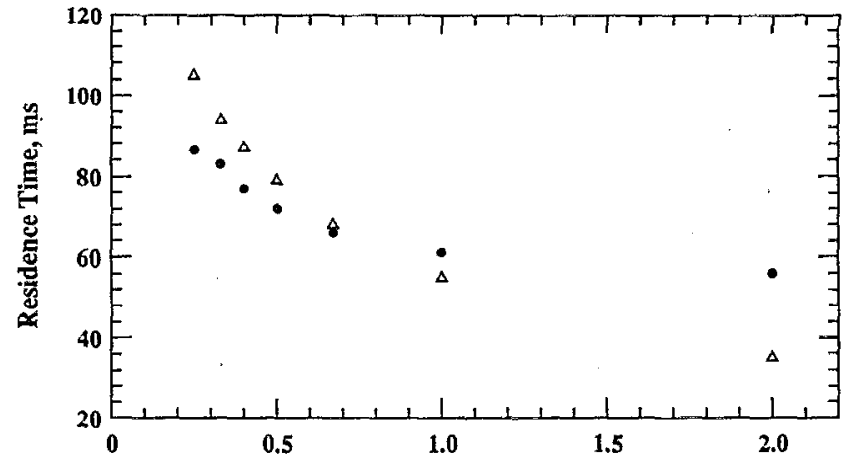

(a)

Inlet Gas Velocity, $\mathrm{m} / \mathrm{s}$

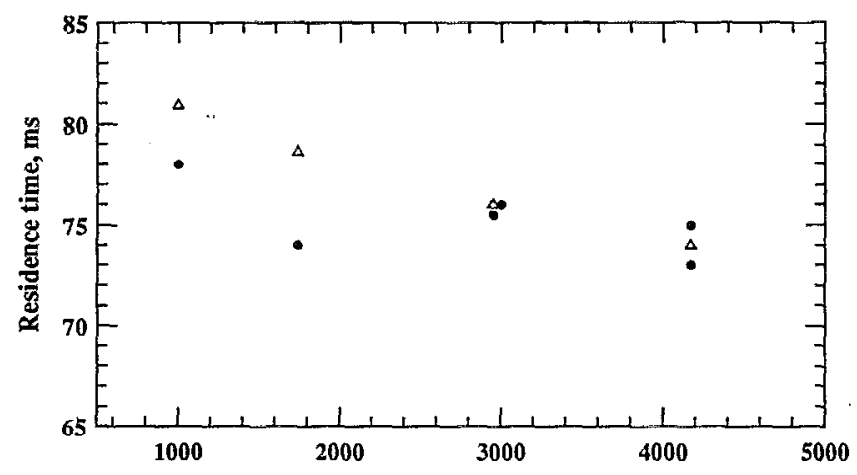

(b)

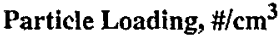

FIG. 11. (a) Measured ( $)$ and calculated $(\Delta)$ residence times during primary pyrolysis for various inlet gas velocities. The furnace temperature is $1840 \mathrm{~K}$, and the inlet loading is 300 particles $/ \mathrm{cm}^{3}$. (b) Measured (๑) and calculated $(\Delta)$ residence times for $55-\mathrm{mm}$ coal particles at various loadings. The furnace temperature is $1740 \mathrm{~K}$, and the inlet gas velocity is $0.5 \mathrm{~m} / \mathrm{s}$.

vanish at higher velocities, except at $2 \mathrm{~m} / \mathrm{s}$, for which the flow is fully turbulent $(\operatorname{Re}=2900)$ and the expression from the laminar boundary layer breaks down. The comparison for various suspension loadings in Fig. 11(b) is much more satisfactory; the discrepancies are inconsequential at every loading.

Given the empirical nature of our gas residence time calculations, temperature profiles will not be convertcd into thermal histories at this time. In the remainder of this paper all reported residence times are measured values.

\section{B. Mass and elemental closure}

In this section, selected results illustrate the closure of mass and elemental balances in individual runs with coal suspensions. Representative results further illustrate how primary and secondary transformations can be resolved. Results from selected oxidation studies complete this survey.

The product distribution from the primary pyrolysis of a high volatile bituminous coal appears in Fig. 12(a). Total weight loss increases as residence times are extended, reaching its asymptotic value of $54 \mathrm{wt} \%$ at $89 \mathrm{~ms}$. Hydrocarbon gas yields have been resolved as $\mathrm{CH}_{4}, \mathrm{C}_{2} \mathrm{H}_{2}, \mathrm{C}_{2} \mathrm{H}_{4}$, 


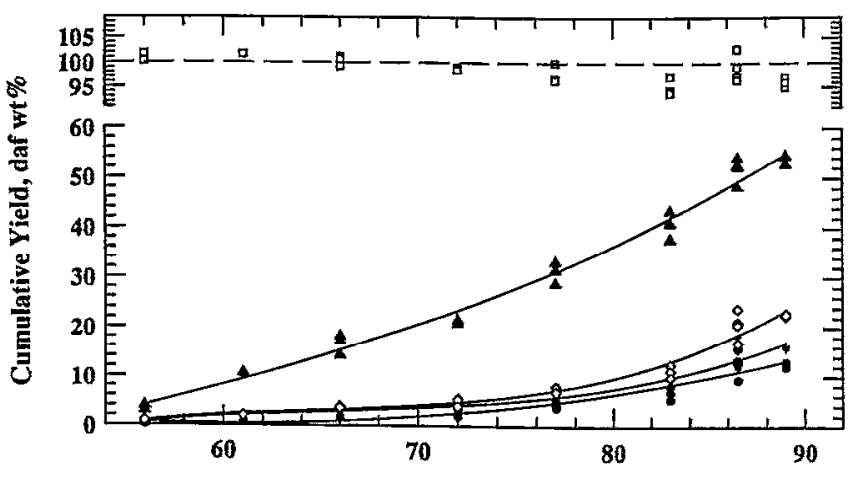

(a)

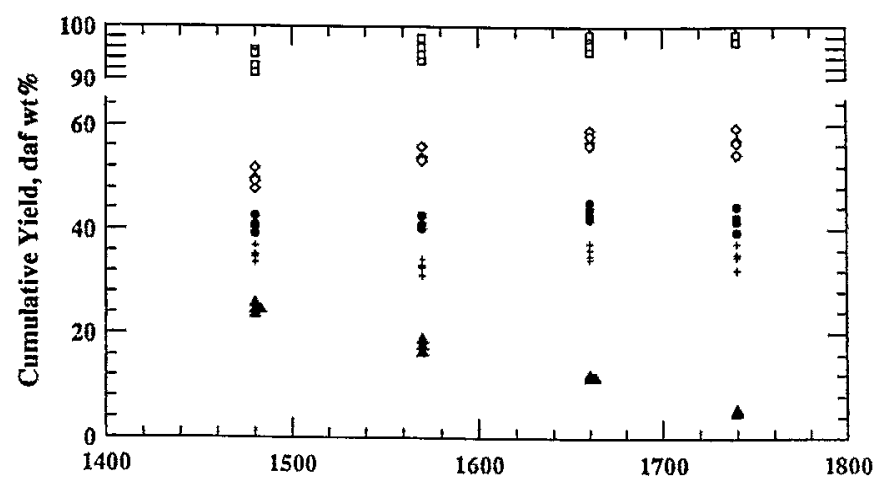

(b)

Wall Temperature, $\mathrm{K}$

FIG. 12. (a) Cumulative product yields for Pittsburgh coal from primary pyrolysis in an $1840 \mathrm{~K}$ furnace. The products are hydrocarbon gases and oils $(\bullet)$, water $(+), \mathrm{CO} / \mathrm{CO}_{2}(\diamond), \operatorname{tar}(\Delta)$, and char ( $\left.\square\right)$. (b) $\mathrm{Cu}$ mulative yields of tar and oils $(\Delta)$, soot $(+), C_{1}-C_{3}$ hydrocarbons $(\bullet)$, $\left.\mathrm{CO} / \mathrm{CO}_{2} / \mathrm{H}_{2}\right)(\diamond)$, and char $(\square)$ during secondary pyrolysis of Pittsburgh coal. Inlet loading is 1200 particles $/ \mathrm{cm}^{3}$ and gas velocity is 0.18 $\mathrm{m} / \mathrm{s}$.

$\mathrm{C}_{2} \mathrm{H}_{6}, \mathrm{C}_{3} \mathrm{H}_{8}$, and $\mathrm{C}_{3} \mathrm{H}_{6}$, aggregate $\mathrm{C}_{4}$ 's and oils, but are shown as a single lump. These data show that weight loss and tar yields are generally reproducible to within $2 \mathrm{wt} \%$. Mass balances typically close to within 5\%, as seen in this case.

As noted before, secondary chemistry is promoted with higher loadings and longer residence times, and regulated by changing the furnace temperature. The data in Fig. 12(b) demonstrate this control strategy with the conversion of tar and oils into soot. As the furnace temperature is increased, tars and oils vanish while the amount of soot in the aerosol increases in tandem. Meanwhile, the total amount of both aerosol products and the total weight loss remain the same. Simply by regulating the hot-zone temperature, arbitrary extents of secondary chemistry can be observed, as gauged by the extent of tar-to-soot conversion. Both the reproducibility and the mass closure in individual runs are satisfactory throughout.

Elemental closures are assigned for carbon, oxygen, and nitrogen from measured distributions of the major hydrocarbon, oxygenated, and nitrogenous products. For fuels as heterogeneous as coals, numerous products must be
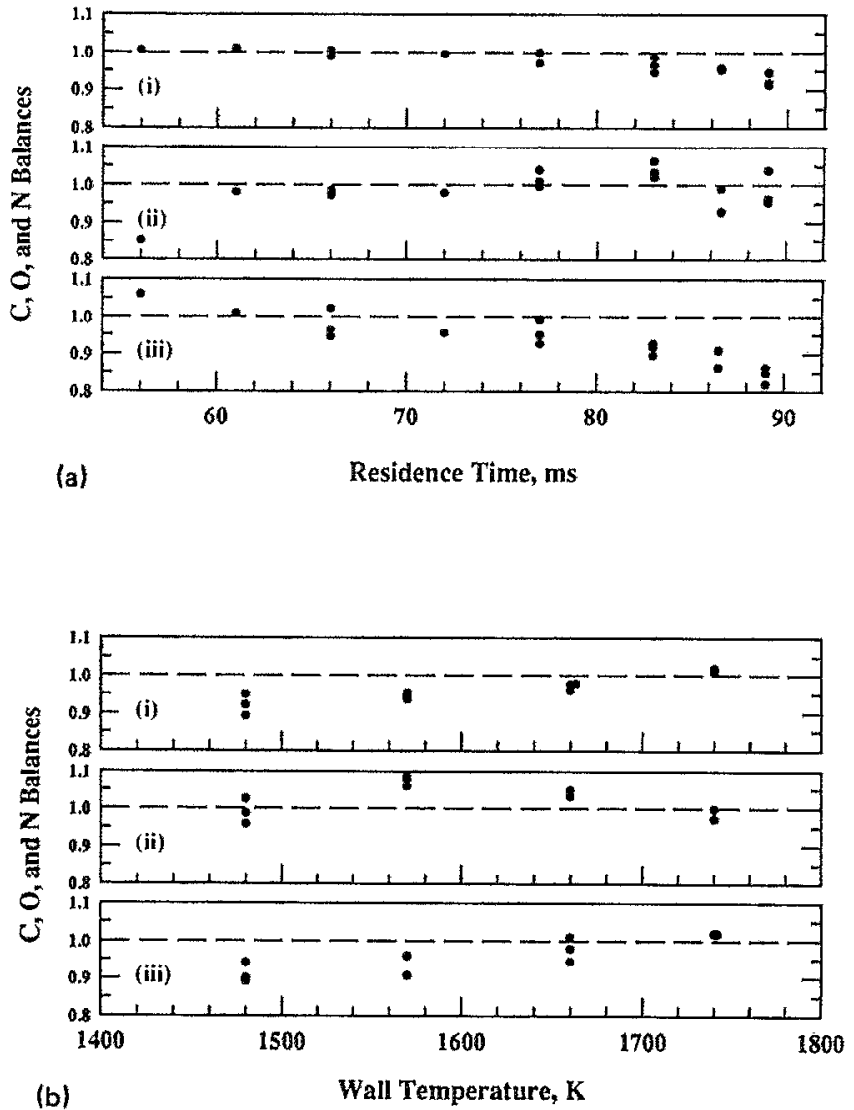

FIG. 13. (a) Elemental closures for (i) carbon, (ii) oxygen, and (iii) nitrogen for primary pyrolysis of Dietz subbituminous coal in an $1840 \mathrm{~K}$ furnace at 300 particles $/ \mathrm{cm}^{3}$. (b) Elemental closures of (i) carbon, (ii) oxygen, and (iii) nitrogen from secondary pyrolysis of Dietz subbituminous coal at $0.18 \mathrm{~m} / \mathrm{s}$ inlet gas velocity and 1200 particles $/ \mathrm{cm}^{3}$.

monitored. Carbon is distributed among char, tar, oils, all of the hydrocarbon gases from $\mathrm{C}_{1}$ to $\mathrm{C}_{4}$, and the oxides of carbon. Oxygen is distributed among char, tar, oils, water, and the oxides of carbon. Nitrogen is distributed among char, tar, oils, HCN, and, perhaps, ammonia. Such product distributions from various coals are reported elsewhere, ${ }^{22.24}$ but the elemental closures associated with them for representative series of runs with a subbituminous coal appear in Fig. 13. For both primary pyrolysis in Fig. 13 (a) and secondary pyrolysis in Fig. 13(b), these three elemental balances are closed to within $5 \%$ in individual runs, with the exception of nitrogen at long residence times during primary pyrolysis and low wall temperature during secondary pyrolysis. This breach of closure is probably an indication of ammonia production. ${ }^{11}$

Adding oxygen to the process stream achieves higher particle temperatures for the same nominal operating condition because of the combustion exotherm. We increase residence times in the $12-\mathrm{cm}$ reactor by extending the quartz tube by $30 \mathrm{~cm}$ between the furnace outlet and quench nozzle. Oxygen is blended with both the sheath and entrainment flows at equal concentrations. The conversion of fuel nitrogen to NO during combustion of a low volatility coal appears in Fig. 14, along with extents of burnout 


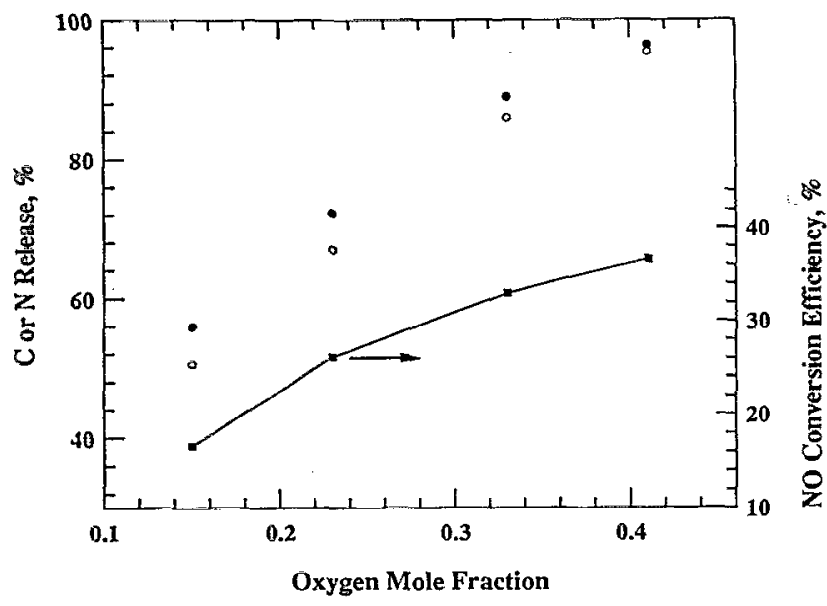

FIG. 14. Extents of carbon (O) and nitrogen (O) release, and conversion of fuel nitrogen to NO (solid curve) during oxidation of Colorado Basin $\mathrm{M}$ medium-volatile bituminous coal at various oxygen levels.

for carbon and nitrogen. In nominal terms for combustion of the whole coal, $14 \%$ and $41 \% \mathrm{O}_{2}$ correspond to equivalence ratios of 1.50 (fuel rich) and 0.52 (fuel lean), respectively. Adding oxygen at progressively higher levels first burns the volatiles, then progressively consumes more char; nearly complete burnout is observed with $41 \% \mathrm{O}_{2}$. No tar or oils and very little soot is recovered at even the lowest oxygen level, so oxidation product distributions are considerably simpler than those for pyrolysis. Consequently, mass and elemental closures are at least as good as seen in Fig. 13.

Only coal suspensions appeared in this performance evaluation, although pyrite and synthetic carbons have also been processed without difficulty. Work with the $25-\mathrm{cm}$ furnace for turbulent flame studies is also proceeding.

\section{ACKNOWLEDGMENTS}

This work was supported by the Electric Power Research Institute, under their Exploratory Research Pro- gram. We are also grateful to the Link Foundation for Dr. Chen's financial support for academic year 1988-89.

'R. D. Nenniger, ScD. thesis, Department of Chemical Engineering, MIT, Cambridge, 1986.

${ }^{2}$ Y. A. Levendis and R. C. Flagan, Combust. Sci. Technol. 53, 117 (1987).

${ }^{3}$ G. J. Haussmann, Ph.D. thesis, Department of Mechanical Engineering, Stanford University, Stanford, 1990.

${ }^{4}$ S. Badzioch and P. G. W. Hawksley, Ind. Eng. Chem. Process. Design Develop. 9, 521 (1970).

${ }^{5}$ F. R. A. Jurgensen, Trans. Inst. Min. Metall. Sect. C 90, 1 (1981).

${ }^{6} \mathrm{Z}$. Asaki, S. Muri, M. Ikeda, and Y. Kondo, Met. Trans. B 16B, 627 (1985).

${ }^{7}$ A. Macek and J. M. Semple, Combust. Sci. Technol. 1, 181 (1969).

${ }^{8}$ S. C. Li, F. A. Williams, and F. Takahashi, Twenty-Second Sympositum (International) on Combustion (The Combustion Institute, Pittsburgh, 1988), p. 1951.

${ }^{9} \mathrm{~J}$. B. Howard in Chemistry of Coal Utilization, 2nd Supplemental Volume, edited by M. S. Elliot (Wiley, New York, 1981), Chap. 12, p. 665.

${ }^{10}$ P. R. Solomon and D. G. Hamblen, Prog. Energy Combust. Sci. 9, 323 (1983).

IJ. C. Chen, Ph.D. thesis, Department of Mečhanical Engineering, Stanford University, Stanford, 1991.

${ }^{12} \mathrm{~J}$. Davies and P. Simpson, Handbook of Induction Heating (McGrawHill, New York, 1979).

${ }^{13}$ H. J. Kostkowski and R. D. Lee, Theory and Methods of Optical Pyrometry, National Bureau of Standards Monograph No. 41 (NBS, Washington, DC, 1962).

${ }^{14}$ B. W. Loo, J. M. Jaklevic, and F. S. Goulding in Fine Particles: Aerosol Generation, Measurement, Sampling and Analysis, edited by B. Y. H. Liu (Academic, New York, 1976), p. 311.

${ }^{15}$ B. W. Loo, R. S. Adachi, C. P. Cork, F. S. Goulding, J. M. Jaklevic, D. A. Landis, and W. L. Searles, presented at the 86th Annual Meeting of the American Institute of Chemical Engineers, Houston, TX, 1979.

${ }^{16}$ P. J.Collin, R. J. Tyler, and M. A. Wilson in Coal Liquefaction Products, edited by H. C. Schultz (Wiley New York, 1983), Vol. 1, p. 85.

${ }^{17}$ R. Siegel and J. R. Howell Thermal Radiation Heat Transfer, 2nd ed. (McGraw-Hill, New York, 1981).

${ }^{18}$ D. B. Anthony and J. B. Howard, Fifteenth Symposium (International) on Combustion (the Combustion Institute, Pittsburgh, 1975), p. 1303.

${ }^{19} \mathrm{~J}$. Freihaut, Ph.D. thesis, Department of Material Science and Engineering, Pennsylvania State University, 1980.

${ }^{20}$ M. A. Serio, Ind. Eng. Chem. Res. 26, 1831 (1987).

${ }^{21}$ R. J. Tyler, Fuel 58, 680 (1979).

${ }^{22} \mathrm{~J}$. Chen and S. Niksa, Energy and Fuels (to be published).

${ }^{23} \mathrm{H}$. Schlichting, Boundary-Layer Theory (McGraw-Hill, New York, 1979).

${ }^{24} \mathrm{~J}$. Chen and S. Niksa, Energy and ruels (to be published). 